\title{
LAS TRIBULACIONES DEL MATERIALISMO: RESPUESTA A MIS CRITICOS
}

\section{ULISES MOIJLINES \\ Universidad Vacional Autónoma de México}

0. En agosto de 1977 se publicó en el n. 26 de esta ::evista mi artículo "Por qué no soy materialista". Encabezad as por este título algo provocativo, expuse lo que a mi entender son dificultades graves inherentes a cualquiera de las formas en que se adopte el materialismo. Mi propósito confeso al redactar ese trabajo fue el de aclarar mis propias ideas $y$, en caso óptimo, las de amigos y colegas con quienes cepartí sobre el tema. De ahí el encabezamiento y el tono algo personal del artículo, que al parecer extrañó, cuando no disgustó, a algunos de mis lectores.

En una época en que millones de seres humanos, de las más diversas procedencias culturales, se declaran de buena fe "materialistas", sentí la necesidad de plantear(m(:) las dos preguntas siguientes: ¿Qué puede significar adortar la doctrina materialista? ¿Cuál sería la justificación para adoptarla (suponiendo que se haya dado alguna respuesta razonablemente clara a la primera cuestión)? A pesar de haber indagado en la voluminosa literatura de y sobre autores supuestamente materialistas, históricos o contemporáne os, filosóficos y no-filosóficos, "vulgares" y "refinados", 110 encontré ninguna respuesta satisfactoria a las dos prę̧;untas anteriores. Por esto me decidí a hacer pública mi de zazón.

Las reacciones al artículo en cuestión han sido, en liss dos años transcurridos al momento de escribir estas líneas, cuantiosas y variadas. Algunas fueron divertidas por $l_{1}$ ) simplistas; otras, penosas por lo viscerales; pero aforte nadamente muchas han sido valiosas y estimulantes. Al cabo de más de dos años de haberme planteado el problema, tengo 
la impresión de haber alcanzado una perspectiva más clara, y eso se lo debo, en gran parte, a mis críticos y comentaristas.

Apenas un año después de la publicación del artículo, se organizó en México una mesa redonda sobre el materialismo, con participantes de diversa extracción filosófica. La variedad de puntos de vista básicamente distintos acerca de la naturaleza del materialismo, que se manifestaron en esa ocasión, confirmaron una vez más mi sospecha de que el materialismo es una doctrina esencialmente confusa y de la que lo menos que puede decirse es que requiere de una radical operación de cirugía conceptual. Algunos meses después apareció el libro de José Ferrater Mora, De la materia a la razón (Madrid, 1979), en el que se recoge y analiza mi tesis anti-materialista básica. En el interín, Enrique Villanueva, Álvaro Rodríguez Tirado, Carlos Pereyra, Mario Otero y Miguel Ángel Quintanilla sucesivamente han publicado sus críticas a mi trabajo. Uno de los temas incluidos en el III Coloquio Nacional de Filosofía en México (cuyo ribete general es "Explicaciones materialistas e idealistas en filosofía") es el del análisis del concepto de materia. En todo este tiempo, numerosos comentarios formulados, de momento sólo verbal o informalmente, han dado también lugar a discusiones estimulantes.

Creo que todo esto muestra que una consideración detallada y crítica de la naturaleza del materialismo (y de cuestiones relacionadas con él, como el monismo ontológico, el reduccionismo y el concepto de materia) era, y sigue siendo, candente. Por ello creo también justificado volver a la carga sobre el tema. A pesar de todo lo que ya se ha dicho sobre él, siento que aún hay puntos oscuros o controvertidos que merecen ser investigados.

En lo que sigue, me dispongo a hacer dos cosas. Primera, resumir brevemente mi posición actual ante el materialismo; es básicamente la misma de hace dos años, aunque, así lo espero, más articulada. En segundo lugar, quiero extenderme en el análisis de y la respuesta a las críticas 
que se han hecho a mi artículo de 1977. Por razones obvias de objetividad, sólo me referiré a aquellos trabajos que han sido publicados. Respecto a las críticas aún no publicadas, no puedo más que esperar que vayan a la prensa lo antes posible.

1. Ante todo conviene aclarar los términos de la discusión. El objeto de mis críticas es una doctrina, llamada "materialismo", que, con diversos matices y modificaciones, pero con una innegable "identidad personal", lleva por lo menos dos mil quinientos años de existencia (en la cultura occidental; en oriente probablemente lleve más). Y entiendo esta doctrina como una ontología monista, es decir, una doctrina que trata de dar una respuesta universal y unívoca a la pregunta: "¿Qué hay en el mundo?”, o si se prefiere: "¿De qué está constituida la realidad?". Por razones a la vez históricas y sistemáticas creo que éste es el sentido genuino (y el máximo atractivo) del materialismo. Es una ontología universal. No quiero decir con ello que no esté conectado con cuestiones epistemológicas, metodológicas, éticas, etc. Toda doctrina ontológica medianamente articulada revela tal tipo de conexiones. Pero ellas son, o bien consecuencias, o bien premisas secundarias, no el núcleo de la doctrina en cuanto tal. El núcleo del materialismo es una tesis ontológica: a la pregunta "¿Qué hay?”, el materialismo responde: "Sólo hay materia"; o, equivalentemente, a la pregunta “¿Qué es lo real?", su respuesta es: "Todo lo real es material, y nada más."

Creo que esta delimitación del materialismo como nuclearmente ontológico no es arbitraria por mi parte, sino que tiene amplia justificación en la historia de las ideas. Aunque no sea éste el momento ni el lugar de hacer aseveraciones historiográficas de gran alcance, sin embargo quisiera hacer notar que es fundamentalmente como ontología que se presentó el materialismo de los atomistas y sofistas griegos, el de los mecanicistas de los siglos xvII y xviII, el de los físicofisiólogos "radicales" del xIx, el de los fisicalistas del xx, 
y el de tantas otras corrientes emparentadas. Todos ellos trataron de caracterizar coherentemente lo real como lo puramente material en algún sentido definido. El hecho de que el materialismo se haya tomado a veces como una posición epistemológica, metodológica o hasta ético-política no ha hecho, en mi opinión, más que confundir los términos de la discusión. Y el origen de esta confusión podría retrotraerse fácilmente a determinadas circunstancias históricas contingentes que han rodeado la discusión en torno al materialismo (por ejemplo, circunstancias científicas, religiosas, éticas o políticas).

La doble caracterización del materialismo como doctrina ontológica por un lado y universal por otro, permite excluir justificadamente del foco de la discusión a toda una serie de posiciones que de algún modo se han visto asociadas históricamente (a veces de manera muy circunstancial) con el materialismo sensu stricto y cuya consideración simultánea no puede hacer más que embrollar el problema. Ejemplos de posiciones que no hay que confundir con el materialismo, y que por tanto excluí de mis discusión tanto en el artículo anterior como en éste, son:

- El realismo epistemológico: la tesis (vaga) de que los seres humanos pueden llegar a conocer "la" realidad y de que ésa es en gran medida independiente de su voluntad. (A veces se expresa esta tesis de manera aún más vaga como la de que "el mundo exterior es cognoscible por mí e independiente de mí".) Se supone que ésta es una tesis equivalente o similar a la de la posibilidad de objetividad en el conocimiento humano. Se trata aquí de un planteamiento genuinamente epistemológico y, en cuanto tal, independiente del materialismo como ontología. No hay ninguna contradicción lógica en ser realista y no-materialista: por ejemplo, puedo creer que conozco una realidad "externa" a mí, pero que ella es de naturaleza espiritual; como tampoco hay ninguna contradicción lógica entre el materialismo y el subjetivismo: puedo creer que yo soy un ente material (según algún sentido de "material" que suponemos especificable), pero que 
también soy lo único que realmente existe en el mundo y que todo lo demás me lo estoy inventando en una especie de sueño (el sueño, por supuesto, también sería un proceso "material" que me ocurre a mí como ente "material").

- El ateísmo (a veces llamado, por los más prudentes, "agnosticismo") : la negación de la existencia de uno o varios dioses, o de seres parecidos, como almas incorpóreas, ángeles, demonios, etc. Esta es ciertamente una posición ontológica, pero no es universal: no se compromete con una caracterización global de la realidad, sino que sólo niega que haya determinadas cosas como dioses, demonios, etc. El materialismo es una tesis mucho más general. Implica el ateísmo, pero no es implicado por él.

- El reduccionismo fisicalista: la tesis según la cual todas las teorías científicas, incluidas las de la psicología, son reducibles a la física. Esta tesis se suele adelantar dentro del contexto de la discusión del llamado "problema mentecuerpo". Lo natural es interpretarla como un punto de vista (o, mejor, un programa) epistemológico y/o metodológico: a saber, un programa para la reconstrucción más adecuada de ciertas relaciones interteóricas (entre la psicología y otras disciplinas). De manera algo forzada, algunos interpretan este programa también como una tesis ontológica (= "lo mental es reducible a lo corporal"). Quizás esto se pueda hacer, aunque no estoy seguro de que tenga mucho sentido. En cualquier caso, nos hallaríamos nuevamente ante una doctrina ontológica parcial, y no universal, como se supone que es el materialismo, puesto que se trataría de una doctrina acerca de los fenómenos mentales solamente.

Es cierto que esta doctrina psicofísica se ha venido llamando "materialismo" dentro de ciertos ámbitos filosóficos. Sin embargo, su nombre genuino debería ser "fisicalismo", o mejor aún, "fisiologismo". Y no se trata sólo de una cuestión de nombres. Como argüiré con más detalle al contestar a algunos de mis críticos, creo que el hecho de que a esa doctrina dentro del problema mente-cuerpo se la haya denominado "materialismo" tiene su doble origen en una confusión entre 
el contexto ontológico y el epistemológico por un lado, y en una evaluación errónea del estado actual de las ciencias y de sus relaciones interteóricas, por otro.

- La teoría marxista del desarrollo histórico de las sociedades, corrientemente (mal) llamada "materialismo histórico": una teoría que afirma la existencia de determinadas correlaciones entre fenómenos socioculturales en general y fenómenos estrictamente económicos, en su evolución histórica. Lo más apropiado es interpretar esta doctrina en parte como una teoría empírica acerca de ciertas regularidades sociohistóricas, $\mathrm{y}$ en parte como un programa metodológico para el uso del llamado "método dialéctico" en el estudio de los fenómenos sociales. En el primer caso, no veo por qué ella tiene que estar más ligada a cuestiones auténticamente ontológicas que, pongamos por caso, la teoría darwiniana de la evolución en biología, o cualquier otra teoría empírica referida a un ámbito restringido de fenómenos de tipo evolutivo. En su segundo aspecto, es decir, como propuesta metodológica, tampoco veo que esté más íntimamente asociada a la ontología que, por ejemplo, un programa metodológico en pro del uso de ecuaciones diferenciales o cualquier otra herramienta heurística en una ciencia empírica cualquiera.

Pero aun cuando estuviéramos dispuestos a interpretar el marxismo como ontología, ésta no sería ciertamente una ontología universal acerca de la composición de la realidad, sino a lo sumo una ontología parcial acerca de la constitución de los objetos macrosociales. (Por supuesto, los teóricos marxistas pueden adoptar, suplementariamente, una ontología materialista universal, por ejemplo, la creencia en el atomismo, como parece que fue el caso del propio Marx; pero eso ya no es un aspecto específico del marxismo, que haya que tratar por separado al discutir el materialismo.)

Como se verá, algunos de mis críticos tomaron como punto de referencia algunas de las tesis o doctrinas anteriores para objetar a mis planteamientos anti-materialistas. De lo que acabo de decir puede desprenderse ya cuál es la línea 
general de mi respuesta a tal tipo de objeciones: simplemente están fuera de lugar. Contraatacar a una crítica del materialismo defendiendo el realismo en epistemología, el fisicalismo en el problema mente-cuerpo o el marxismo en el estudio de la sociedad no es defender el materialismo; es defender otra cosa, que no es mi problema. Esto aparecerá más claro cuando analice las objeciones de cada uno de mis críticos con detalle.

Mi propósito, pues, fue y es discutir el materialismo como monismo ontológico, y más específicamente, como un monismo que afirma que todo es materia o que "todo lo real es material". Como bien ha visto Quintanilla, las objeciones que presenté en mi artículo anterior pueden resumirse en dos argumentos: uno de carácter específico referido propiamente al materialismo, el otro de carácter más general en contra de cualquier forma de ontología monista. El argumento específicamente anti-materialista es, resumidamente, que, dado que la noción de "materia" está hoy día tanto o más oscura que nunca, afirmar "todo es materia" es una afirmación por lo menos igualmente oscura y aun más aventurada. En cuanto al argumento anti-monista general, su punto de partida es la situación de nuestro conocimiento científico actual, para argüir que, en vez de un monismo, es mucho más plausible un pluralismo, que admita que la realidad $(0$, mejor dicho, la multiplicidad de realidades) puede subsumirse bajo distintas categorías ontológicas básicas y mutuamente irreducibles. Disiento de Quintanilla cuando afirma que estos dos argumentos, el específico y el general, son incompatibles entre sí. Son independientes, pero no incompatibles. Sobre este punto volveré al tratar las críticas de Quintanilla.

Ambos argumentos, tanto el específico como el general, hacen uso implícito de dos criterios metafilosóficos (o, si se quiere, metaontológicos). Una doctrina monista es una doctrina que afirma que hay un solo concepto básico con contenido, bajo el cual se puede subsumir cualquier tipo de realidad. (Ésta es la única forma que veo de precisar lo que es o pretende una doctrina monisia.) En el caso del materia- 
lismo, este concepto privilegiado no puede ser otro sino el expresado mediante el predicado "es materia" o "es material". Pues bien, para que una doctrina de esta clase sea admisible, deben cumplirse los dos requisitos siguientes:

$(A)$ Debemos disponer de criterios razonablemente claros y efectivos ${ }^{2}$ que determinen bajo qué condiciones se puede aplicar el concepto fundamental de la doctrina en cuestión y bajo cuáles no; es decir, debemos disponer de criterios que nos permitan decidir, al menos en principio y con cierta probabilidad, para todo ente $x$, si estaríamos dispuestos a admitir que $x$ es $P$ o bien que $x$ no es $P$ (siendo $P$ el predicado que expresa el concepto fundamental). Si no se cumple esta condición, entonces la doctrina en cuestión es arbitraria y confusa, o arbitraria y tautológica; en cualquier caso, arbitraria.

(B) La pretendida aplicación universal del concepto en cuestión ("materia" en nuestro caso), atendiendo a los criterios presupuestos en $(A)$, debe estar sustentada suficientemente por las teorías científicas vigentes. De lo contrario, la doctrina carece de fundamento científico, es puramente especulativa en el mal sentido de la palabra.

Ahora puedo resumir mi argumentación básica contra el materialismo específicamente y contra el monismo en general. La tesis es que estas doctrinas no cumplen las condiciones $(A)$ y $(B)$ expuestas; o, dicho más exactamente, que si tratamos de que se cumpla $(A)$, entonces no se cumple $(B)$, y si tratamos de que se cumpla $(B)$, entonces no se cumple $(A)$. En efecto, en la primera parte de "Por qué no soy materialista" mostré cómo, al intentar satisfacer la condición $(A)$, es decir, al intentar hacer del materialismo una doctrina que no sea confusa ni tautológica, chocamos con resultados vigentes de las teorías científicas y/o de un análisis lógico riguroso. (El caso más claro y más importante de esta situación es el intento de salida atomista.) Por otro lado, la otra estrategia usada por los materialistas es

\footnotetext{
1 Pero no necesariamente formales ni definicionales, como algunos críticos han supuesto que yo exigía.
} 
tratar de satisfacer $(B)$ a como dé lugar. Se arguye entonces que, por definición, el materialismo es compatible con cualquier resultado científico vigente, que "materia" designa simplemente cualquier cosa que los científicos actuales acepten como real; con lo cual es obvio que la doctrina se tautologiza, pues al definir primero la materia simplemente como lo que es aceptado como real en una época determinada y afirmar después que "todo lo real es materia", evidentemente lo único que se está diciendo es que "todo lo real es real".

Por todo ello concluí en mi artículo que, dados los resultados actuales del conocimiento científico y del análisis filosófico, el materialismo es una doctrina implausible. Quizás convenga hacer notar una vez más que lo único que sostengo es que el materialismo es implausible, no imposible. Con esto pretendo ser más cauto que muchos de mis adversarios materialistas. En efecto, puedo imaginar situaciones en que el materialismo resultara más plausible. Por ejemplo, es imaginable que una depuración concienzuda de nuestras intuiciones sobre el concepto de materia, combinada con cierta interpretación apropiada de la teoría de la relatividad generalizada como única teoría fundamental, diera lugar a una visión del universo que se asemejara suficientemente a lo que hoy entendemos por materialismo. Sin embargo, esto es aún música celestial, $y$ por lo pronto me parece más sensato adherirse a un pluralismo ontológico tan liberal como parezca conveniente.

2. Paso ahora a la consideración de los trabajos publicados hasta la fecha que incluyen reacciones a mis argumentos antimaterialistas. Ello me permitirá no sólo responder a las objeciones de mis críticos, sino completar algunos de los puntos generales que se han hecho en el apartado precedente.

Ad Ferrater Mora:

Mi respuesta al comentario de Ferrater Mora en De la ma- 
teria a la razón (pp. 23-24) no puede ser muy polémica, puesto que este autor concuerda con mi argumentación antimonista general. La reconstrucción que Ferrater Mora da de mi argumento y de sus consecuencias para una ontología materialista es impecable. Ahora bien, lo que me desconcierta en la posición de Ferrater Mora es que, a pesar de reconocer las graves dificultades de cualquier doctrina monista $\mathrm{y}$, en particular del materialismo, a renglón seguido nos comunica que "persistirá en el empeño" de adscribirse a una especie de monismo paramaterialista, que ciertamente él llama "monismo sui generis" (para distinguirlo de las formas criticadas), pero que, a mi entender, no deja de ser sujeto a algunas de las críticas ya expuestas. Ferrater Mora caracteriza su monismo de la siguiente forma: "Una de las tesis de esta posición es la de que si algo es real, es un hecho, proceso o fenómeno natural o está conectado de alguna manera con algún hecho, proceso o fenómeno naturales. Los hechos, procesos o fenómenos naturales constituyen lo que se llama, para abreviar, 'la Naturaleza', y ésta comprende ante todo el universo 'material'" (op. cit., pp. 23-24).

Parece pues que Ferrater Mora identifica lo material con lo natural, o por lo menos como "la base" de todo lo natural, para pasar entonces a su tesis monista de que "todo lo real es natural", la cual, según la identificación propuesta, sería una forma de materialismo.

No puedo por menos que ver en esta tesis un ejemplo de la estrategia tautologizante o trivializante del materialismo en sus formas avanzadas, que he criticado más arriba. En efecto, si identificamos lo material con lo natural para pasar a afirmar que "todo lo real es natural" o, equivalentemente, "todo lo real es material", pero sin dar una caracterización no-vacua, efectiva de "natural", entonces estamos ante el mismo problema que reseñé en mi artículo. El predicado "es natural" es, o bien confuso, o bien trivial (esto último si se le entiende como idéntico a "es real"), y la tesis, por tanto, o es confusa, o es tautológica. Sustituir "la materia" por "la Naturaleza" no arregla las cosas; las deja igual. 
(En este sentido, el naturalismo se enfrenta a los mismos problemas que el materialismo.) Es posible que Ferrater Mora, al subrayar el carácter natural de lo real, lo que quiera dejar sentado es que no cree en la realidad de entes llamados "sobrenaturales", como dioses, demonios, etc. Esta tesis ciertamente poseería más contenido que la anterior. Pero entonces no se trataría de una tesis monista general, sino de una tesis particular, a saber, el ateísmo, que, como he argüido antes, no debe confundirse con el materialismo.

\section{Ad Villanueva, Rodríguez Tirado \& Pereyra:}

Trataré juntas las objeciones que me han hecho estos autores, ya que parten básicamente de la filosofía de la mente y revelan muchos puntos en común. ${ }^{2}$

Una objeción muy general que me hacen estos tres autores es la de que mis críticas al materialismo están a lo sumo justificadas con respecto a lo que ellos llaman el materialismo "lego" o "vulgar" pero no respecto al materialismo "filosófico", que sería, aparentemente, el único digno de discutirse. Confieso que no entiendo el sentido de esta distinción tajante entre materialismo filosófico y materialismo lego. Por supuesto, hay personas con diversos niveles culturales y distinto entrenamiento profesional que se autotitulan materialistas, y el grado de precisión y claridad con que articulan sus creencias materialistas variará de unas a otras. Pero no creo que de ello pueda inferirse que hay un materialismo filosófico esencialmente distinto del "lego", al que por principio no se le apliquen mis críticas. La tarea del filósofo aquí, lo mismo que en tantos otros casos parecidos de análisis conceptual, sólo puede consistir en tratar de elucidar y sistematizar las concepciones presistemáticas del "vulgo" no-filosófico. Y mi tesis justamente era, y es, que cualquiera de esos intentos de elucidación está condena-

2 Pereyra añade a sus críticas desde el punto de vista del problema mentecuerpo un comentario sobre la naturaleza del materialismo histórico. A él me referiré después. 
do al fracaso (a menos que, bajo el membrete de "materialismo", el filósofo se invente una doctrina cuyo parecido con el original sea irreconocible).

Además, ¿son realmente tan "legos" muchos de los nofilósofos que se declaran materialistas en el sentido por mí criticado? Muchos de los científicos naturales, ideólogos, activistas políticos, críticos de la religión, etc., que se declaran materialistas pretenden hacerlo fundadamente, con buenas razones, después de haber reflexionado sistemáticamente. No creo que las premisas y conclusiones de sus argumentos pro-materialistas sean tan radicalmente distintas de las de los filósofos. A lo sumo, lo que distingue a estos últimos de los primeros es el uso de una jerga algo técnica y esotérica. Pero la jerga es inesencial.

Creo ser justo con el materialismo al suponer que no se trata sólo de una teoría recóndita, pergeñada a base de tecnicismos filosóficos ininteligibles al común de los mortales, sino que se trata más genuinamente de una concepción del mundo, hasta podríamos decir, una concepción cosmológica grandiosa ( $\mathrm{y}$ por supuesto muy ambiciosa), que ha jugado un gran papel en el desarrollo intelectual de nuestra cultura. Creo que, a pesar de todas las matizaciones, distinciones y tecnicismos que los filósofos puedan introducir, hay un pathos común, un hilo conductor compartido por todas las personas que se confiesan materialistas: ya sea un profesional del análisis filosófico que admite las tesis más abstrusas de Davidson, o bien un físico entusiasmado con la introducción de los quarks porque cree que con ellos quedará definitivamente establecido que en el universo sólo hay una clase de cosas, a saber, quarks; o en fin, también el escolar inexperimentado que, para mostrar su rebeldía ideológica, espeta a sus educadores religiosos: "Dios no existe porque todo es materia y nada más." "Todo es materia": sigo creyendo que este eslogan no es inadecuado para resumir el carácter cosmológico de la Weltanschauung materialista. Es este eslogan el que mejor sintetiza el hilo conductor común a todos los materialistas. Si no, ¿cuál podría ser? La afirmación ontológi- 
ca universal del materialismo es la que le confiere su atractivo para tan gran número de personas de tan diversa procedencia y nivel cultural, y también, claro está, la que le produce sus graves problemas. Era contra ese denominador común de todos los materialistas que iba dirigido mi artículo. Si se le elimina del horizonte de la discusión, entonces ciertamente mi crítica deviene carente de objeto, pero entonces también resulta difícil ver en qué radica la gracia de una proclamación materialista.

Relacionado con lo anterior, está un planteamiento por parte de mis críticos que me parece inadecuado, y además asombroso. Según ellos, el problema del materialismo es totalmente independiente de los resultados y concepciones de la ciencia moderna, en particular de la física, acerca de lo que pueda ser la materia. Rodríguez Tirado, por ejemplo, asevera: "la física de partículas tiene poco o nada que decir respecto al tema sujeto a discusión" ("¿Qué es la materia?", p. 88). Y Pereyra: "La estrategia adecuada ... para dilucidar la pertinencia de adscribirse o no adscribirse al materialismo filosófico no pasa por el examen del concepto "materia" ("Sobre el materialismo. Réplica a Moulines", p. 9).

Para mí, esta posición es muy sorprendente, puesto que me parece obvio que el término "materialismo" ha de tener alguna relación con el término "materia", y no nada más la de una casualidad filológica. Hay una estrecha relación conceptual entre "materialismo" y "materia". El materialismo, sea cual sea la ulterior caracterización que de él se ofrezca, es una doctrina que da alguna clase de preeminencia a un tipo de realidad que llamamos "materia". Si no es ése el sentido del materialismo, entonces, ¿de qué estamos hablando? Ahora bien, si el concepto de materia interviene esencialmente en una caracterización adecuada del materialismo, como me parece obvio, entonces también me parece claro que una parte del análisis del materialismo debe estar dedicada al análisis del concepto de materia. Y es aquí donde no sólo los filósofos, sino también los físicos (o, al menos, los filósofos de la física) tienen manifiestamente algo que 
decir. Divorciar el análisis filosófico del concepto de materia de los resultados generales de la física moderna me parece una forma inaceptable de proteccionismo a ultranza en favor de una supuesta autonomía de la filosofía. En cuestiones ontológicas, ciencia y filosofía están casadas: ninguna de las dos puede actuar por su propia cuenta.

Quizás la objeción más fuerte y recurrente en los tres autores mencionados es la de que no trato de la cuestión del materialismo dentro del contexto del problema mentecuerpo, que es, al parecer, la única forma de tratar el materialismo que les parece filosóficamente interesante y fructífera, o, al menos, la principal forma de hacerlo. La reducción de los conceptos mentales a los físicos es, según Villanueva, "una forma paradigmática de abordar el materialismo" a la que yo no hago justicia. "En el problema de la mente y el cuerpo, por ejemplo, se llega al materialismo en una forma oblicua, pero no por ello carente de fuerza. Lo que un filósofo se plantea a este respecto es la cuestión acerca del hecho de la conciencia ... Los filósofos materialistas tratan de hacer posible y plausible la creencia de que la conciencia no es un hecho último, y en esta forma dan contenido a la proposición 'sólo la materia existe'." ("Acerca de la creencia filosófica en el materialismo", pp. 107-108.)

En la misma línea, Rodríguez Tirado se extraña de que me preocupe por el paralelismo conceptual entre entidades astrológicas y ciertas entidades de la física moderna, y no, en cambio, por entidades mentales como deseos, intenciones, etc. Para él, "discutir al materialismo ... es discutir, entre otras cosas, la relación que existe entre teorías psicológicas y teorías neurológicas" ("¿Qué es la materia?", p. 82). Más adelante se vuelve más contundente respecto a lo que él cree que debe ser el tema del materialismo: "la tesis del materialismo stricto sensu estriba en considerar a los fenómenos mentales como meros fenómenos físicos, en particular, eventos, estados o procesos neurofisiológicos en el sistema nervioso central del cerebro humano" (op. cit., p. 87).

Con un matiz distinto, pero dentro del mismo contexto, 
Pereyra caracteriza el materialismo "genuino" como una determinada respuesta al problema mente-cuerpo: "Según la definición más difundida, materialismo es el nombre dado a un conjunto de doctrinas concernientes a la realidad en cuanto tal, que parte del reconocimiento de la prioridad de la naturaleza sobre el espíritu, de la materia sobre la conciencia, o de lo extra-mental sobre lo mental" (op. cit., p. 9). ${ }^{3}$ Más abajo, su caracterización se vuelve más precisa: "adoptar una posición materialista significa explicar los estados, sucesos o procesos mentales a partir de los estados, sucesos o procesos extra-mentales o materiales" (op. cit., p. 9).

En la primera parte de este artículo he apuntado ya por qué no creo apropiado que el materialismo se discuta exclusivamente, ni siquiera centralmente, en el contexto del problema mente-cuerpo. El hecho de que en la filosofía analítica contemporánea frecuentemente se le haya discutido desde este punto de vista no tiene por qué impresionarnos especialmente. No sería la primera vez en la historia de la filosofía que por inercia o falta de espíritu crítico se perpetúa una confusión elemental. Lo que Villanueva, Rodríguez Tirado y Pereyra, como tantos otros que discuten el tema desde esta perspectiva, tienen en mente no es el materialismo propiamente, sino el fisicalismo, o mejor dicho, el fisiologismo, es decir, una tesis parcial acerca de la relación entre la psicología y la neurofisiología (tesis que, además, es de carácter fundamentalmente metodológico, y sólo subsidiariamente de carácter ontológico). Identificar el materialismo con la tesis de que la psicología es reducible a la fisiología, además de confundir el contexto ontológico con el metodológico, sólo puede ser debido a un prejuicio tomado acríticamente por muchos filósofos contemporáneos: a saber, el de que está fuera de toda duda que la ontologia de las ciencias físiológicas es materialista. Pero esto es precisamente lo que se cues-

3 Nótese la doble identificación que hace Pereyra de lo material con lo natural y con lo extra-mental. Sobre el carácter problemático de la primera ya me he extendido al comentar la posición de Ferrater Mora; la segunda identificación será examinada en seguida. 
tiona. Si no está ni siquiera claro que algunas de las teorías fisicas vigentes adopten una ontología materialista (como aduje en mi artículo anterior), menos claro aún estará que la adopte la fisiología y, a fortiori, la psicología.

La tesis reduccionista de psicología a fisiología sólo estaría conectada realmente con el materialismo admitiendo las siguientes premisas:

(I) Disponemos de un concepto suficientemente preciso de la relación de reducción entre teorías.

(II) Todas las teorías psicológicas existentes son reducibles a teorías fisiológicas.

(III) Todas las teorías fisiológicas existentes son reducibles a teorías físicas.

(IV) Todas las teorías físicas existentes son reducibles a una única teoría fundamental, o a unas pocas teorías fundamentales.

(V) La ontología de esa(s) teoría(s) fundamental(es) es estrictamente materialista.

Tan sólo admitiendo esta serie de supuestos podríamos afirmar que la adopción del materialismo es pertinente para una determinada solución del problema mente-cuerpo. Ahora bien, me parece claro que las cinco premisas anteriores son, dada la situación actual de las ciencias, sumamente dudosas. Sólo para (I) hay algún prospecto razonable de llegar a una solución satisfactoria partiendo de trabajos recientes y sumamente técnicos en filosofía de la ciencia. Sobre el resto de las premisas, lo único que podemos decir es que, tomadas en conjunto, se asemejan al cuento de la lechera. En particular, es la última la que ataqué en mi artículo. $\mathrm{Y}$ basta que falle esa premisa para que la identificación del materialismo con cualquier posición adoptada en el problema mentecuerpo resulte carente de fundamento.

Por esta razón no traté del problema mente-cuerpo en mi discusión del materialismo: porque creo que las dificultades graves del materialismo aparecen mucho antes de que ten- 
gamos que recurrir a entidades específicas de la psicología; las dificultades aparecen, por así decir, ya en la base de la (supuesta) jerarquía de las ciencias: en la ontología de la física de fundamentos. Si no está claro en absoluto que la física fundamental se base en una ontología materialista (como argüí anteriormente), entonces a fortiori es menos claro todavía que cualquiera de las soluciones específicas que se propongan al problema mente-cuerpo apoye el materialismo. Aun suponiendo que se pudiera mostrar que la psicología es reducible a la física en algún sentido preciso, no se habría avanzado ni un paso en la justificación de una cosmovisión materialista, mientras no se hubiera descartado convincentemente la posibilidad de una ontología no-materialista para la física. Esta posibilidad no es una mera elucubración esotérica de mi parte. Se han dado, histórica y contemporáneamente, sistemas articulados (por lo menos igual de articulados que el materialismo) que pretenden fundamentar la física en una ontología no-materialista. Ejemplos: la monadología de Leibniz y el sistema análogo de Whitehead, para quienes los constituyentes últimos de la realidad física son entidades espirituales parecidas a lo que usualmente se ha denominado "almas"; el subjetivismo de Wigner, Savage y otros, para quienes la base ontológica de la física cuántica (la parte supuestamente más fundamental de la física actual) está constituida por los estados mentales o creencias subjetivas de los propios físicos; el geometrismo de Chew y el último Heisenberg, entre otros, quienes ven la única salida a las agobiantes dificultades y paradojas de la física de partículas en admitir que las unidades últimas de análisis físico no son partículas materiales, sino formas matemáticas puras (un poco según las viejas ideas de Pitágoras y Platón).

Espero que quede claro que no estoy abogando por ninguna de estas alternativas de fundamentación no-materialista de la física. Tampoco las estoy rechazando. No es cuestión ahora de discutir su validez o grado de probabilidad. El único punto que me interesa señalar es que estas alternativas 
(y otras parecidas, quizás menos "épatantes") existen de manera sistemática y articulada en la literatura, y que mientras no se haya argüido convincentemente (con buenos argumentos y no sólo a través de reacciones emocionales, como suele suceder) que no son viables por principio, no habremos avanzado en la justificación del materialismo, sean cuales sean las posiciones adoptadas en el problema mente-cuerpo. (Para decirlo de forma un poco burda: si resultara que el cuerpo es un conjunto de mónadas leibnizianas como la mente, entonces podríamos reducir lo mental a lo fisiológico todo lo que quisiéramos, y seguiríamos teniendo un sistema espiritualista.)

\section{Ad Pereyra como materialista histórico:}

Además de criticar mi posición dentro del contexto del problema mente-cuerpo, Pereyra se hace portavoz de un sentimiento de malestar que parece ser generalizado entre los estudiosos del marxismo que leyeron mi artículo: la teoría marxista del desarrollo de las sociedades se suele denominar "materialismo histórico", y en mi trabajo no hago la menor referencia a esta forma de materialismo ni presento argumentos que parezcan relevantes para él.

En la primera parte del presente artículo ya he aclarado en términos generales por qué me parece que una discusión del marxismo no viene al caso cuando se trata de considerar el materialismo como ontología universal. El marxismo proporciona, a lo sumo, una ontología para ciertas teorías sociológicas; y nuevamente podríamos paralelizar aquí la situación con el caso de la posición fisiologista en el problema mente-cuerpo. Para que la supuesta ontología introducida por los marxistas tuviera algo que ver con el materialismo, deberíamos asumir un razonamiento como el siguiente: la sociología es reducible, a través de una larga cadena de reducciones a disciplinas intermedias (quizás psicología, o economía, o Dios sabe qué), en último término, a "la" teoría física fundamental cuya ontología se admite que es estricta- 
mente materialista. Pero, por razones análogas a las expuestas frente al fisiologismo en el problema mente-cuerpo, nada de eso parece ser plausible hoy día. Por supuesto, muchos teóricos marxistas declaran ser, al menos verbalmente, antireduccionistas. (Éste parece ser el caso de Pereyra.) Pero entonces resulta aun menos claro en qué sentido la teoría marxista puede tener algo que decir sobre el problema del materialismo. Hacia el final de su artículo, el propio Pereyra se plantea la pregunta crucial: ¿por qué llamar a la teoría marxista "materialismo histórico"? Su respuesta es: "En virtud de la función central que desempeña la producción material en la reproducción histórica de la sociedad" (op. cit., pp. 9-10). Esta respuesta es a todas luces insatisfactoria porque no aclara nada: el calificativo "material" dentro del término "producción material" aparece simplemente como un adorno superfluo en tanto no se aclare su referencia. En efecto, ante la definición dada por Pereyra, podríamos seguir preguntando: ¿por qué llamar "materiales" a ciertas formas de producción? Aun admitiendo que haya formas de producción más básicas que otras para explicar el desarrollo social y económico, ¿qué tiene que ver esto con el materialismo? Éstas son las cuestiones candentes cuya respuesta se exige para que quede claro por qué se llama a la teoría marxista "materialismo histórico". Pereyra no nos dice nada acerca de ellas.

Supongamos, como se suele hacer en este contexto, que "material" en el término "producción material" se refiere a los factores económicos y/o tecnológicos de la producción de bienes. Entonces, decir que la producción material es central para la historia de la sociedad es decir sencillamente que los determinantes económicos y/o tecnológicos son centrales para el desarrollo de la sociedad. Pero no logro comprender en qué forma esto apoya una ontología materialista. Podriamos perfectamente asumir una ontología espiritualista universal y hacerla compatible con la preeminencia de los aspectos económicos y tecnológicos en la explicación sociológica. Para decirlo nuevamente de una forma algo brutal: 
herramientas y mercancías, obreros y capitalistas, todo ello podría no ser más que conjuntos de mónadas espirituales, y por mucho que les diéramos la prioridad ontológica sobre otros factores sociales, no habríamos adelantado nada en nuestra justificación del materialismo.

Por supuesto, no pretendo negar el hecho histórico de que Marx y sus colaboradores de la segunda mitad del siglo XIX simpatizaron con el materialismo como ontología tal como lo entendemos aquí. No en vano el propio Marx escribió una tesis doctoral erudita sobre el atomismo griego mucho antes de que elaborara su teoría socioeconómica. Pero hay que ubicar este hecho en su circunstancia histórica, como una asociación contingente de ideas debida a la peculiar configuración ideográfica de la atmósfera cultural alemana a mediados del siglo xrx. El famoso "Materialismusstreit", que tanto inflamó los corazones, más que los cerebros, de los intelectuales alemanes de esa época, tuvo su origen fundamentalmente en el ataque que iniciaron jóvenes científicos "radicales", especialmente fisiólogos, como Du Boys-Reymond, Brücke, Helmholtz, Virchow, etc., contra el vitalismo y la Naturphilosophie imperantes, y contra su asociación con la filosofía idealista alemana. Este ataque se generalizó y popularizó algo más tarde a través de divulgadores como Büchner, Vogt y otros "vulgomaterialistas". El rechazo virulento de la Naturphilosophie se asoció, por razones muy específicas de la cultura alemana de la época (cuyo pivote fueron los acontecimientos de 1848-49), por un lado con actitudes ideológicas "progresistas" (democráticas, humanistas, antireligiosas, anti-establishment académico) y por otro con una cosmovisión vagamente materialista, según la cual todo en el universo, incluido el ser humano y sus producciones culturales, "no es más que materia en movimiento" (Büchner). Que el Materialismusstreit fue un fenómeno propio de la cultura alemana de mediados del xIx lo prueba el hecho de que, a pesar de su virulencia en Alemania, apenas tuvo repercusión alguna en Francia y los países anglosajones, donde las modas intelectuales eran otras. En esa atmósfera, cual- 
quier intelectual alemán se sentía constreñido a tomar algún punto de vista con respecto a la polémica "idealismo-materialismo"; y ya es sabido cuál tomó Marx. Pero todo eso es metodológicamente independiente de las concepciones marxianas sobre la sociedad humana. Las teorías del valor, de las crisis económicas, de los sucesivos modos de producción, de las relaciones entre las clases sociales, todo eso tiene poco - nada que ver con una ontología materialista: esas teorías pueden mantenerse o refutarse con independencia de que el mundo esté constituido o no por átomos materiales, mónadas espirituales o cualquier otra cosa.

\section{Ad Otero:}

El punto central de desacuerdo en Otero es mi exigencia de que una doctrina materialista se base en un concepto claro de materia. Este requisito le parece exagerado. Tratar de fundamentar el materialismo en una noción precisa de materia sería una tarea imposible, o al menos sobrehumana, porque eso presupondría una teoría final sobre la constitución del universo, un estadio de la evolución científica que, evidentemente, no hemos alcanzado y probablemente no alcanzaremos jamás. En relación con esto, y en términos más formales, Otero sostiene ("Sobre una clase de argumentos antimaterialistas", p. 7) que tratar de construir un predicado con contenido que distinga entre lo que existe y lo que no existe equivaldría a tratar de construir la ciencia toda - lo cual sería un absurdo práctico, si no teórico. Para Otero, el valor del materialismo estriba no tanto en proponer una cosmología conceptualmente bien delineada, sino un programa de investigación, que irá precisando sus conceptos. a medida que se desarrolle.

Admito que un atractivo central del materialismo podría ser, y de hecho ha sido históricamente, el de encaminar la

\footnotetext{
- En Alemania, a diferencia de Francia o Inglaterra, se suponía que ésos. eran los dos únicos términos básicos de cualquier discusión filosófica que valiera la pena.
} 
investigación científica por determinados derroteros y que, para un programa heurístico de esta índole, no es pertinente exigir que se disponga de una teoría final sobre la estructura del universo. También reconozco que éste es un punto que podría tener cierta importancia en la discusión del materialismo, sobre todo desde el punto de vista metodológico, y que yo no mencioné en mi artículo. En este sentido, Otero ha señalado una laguna en los términos de mi planteamiento anterior. No obstante, creo que el mostrar esa laguna no invalida mi crítica del materialismo. En primer lugar, lo que no admito es que mi exigencia fuera exagerada. Pedir que una doctrina materialista se apoye en una noción mínimamente clara y científica de materia no equivale a exigir una teoría final del universo. No veo cómo Otero podría establecer tal equivalencia; en todo caso, no la argumenta en su trabajo. Me parece obvio que la primera exigencia es mucho más débil y razonable que la segunda. Es más, existen ejemplos de conceptos de aplicación muy general en la descripción física del universo, como "energía" o "campo", que son suficientemente precisos y operativos, sin que por ello estemos presuponiendo una teoría definitiva que los contenga. Todo lo que requiero es que "materia" tenga un nivel comparable de precisión y cientificidad. En realidad, históricamente ya alcanzó ese nivel, o casi, durante una etapa de la historia de la ciencia: básicamente dentro del atomismo clásico. Pero en la actualidad creo que se puede afirmar que ya no es así. El concepto de materia ha sufrido una evolución de signo contrario al de otros conceptos básicos de la descripción física del universo: ha ido perdiendo sucesivamente su precisión y contenido, para devenir cada vez más una noción vacua y confusa.

Ello explica también por qué, a mi entender, el materialismo ha ido perdiendo su atractivo genuino, incluso como el programa heurístico que pretende Otero: las líneas de investigación que, supuestamente, toman el concepto de materia como central o básico (en la medida en que todavía se den en la ciencia de facto) se han convertido en "programas 
degenerativos", para usar el término de Lakatos. Esto no podía ser de otro modo, dado que la noción misma de materia, cuestionada desde diversos ángulos de la evolución cientifica reciente, se ha volatilizado. Y ya he explicado en mi respuesta a otros críticos por qué un "materialismo sin materia" me parece una incongruencia.

Otra objeción que me hace Otero es que, al criticar el materialismo en general, estoy presuponiendo que existe un núcleo común a todas las doctrinas denominadas "materialistas"; pero que no doy una prueba de ello. En realidad, no sé cómo se podría probar un supuesto ideográfico de este tipo; sería como pedir "pruebas" de que existe un núcleo común a todo lo que llamamos "cristianismo" o "socialis. mo". No creo que en la historia de las ideas se disponga de pruebas formales de esta clase; sin embargo, ello no obsta para que estudiemos y critiquemos cosas como el cristianismo, el socialismo o el materialismo. De lo contrario, la noción misma de historia de las ideas resultaría imposible.

Por lo demás, admito que podría defenderse con plausibilidad que, en la actualidad, la idea del materialismo ha llegado a tal grado de descomposición conceptual que ya no puede hablarse con propiedad de un núcleo común a todas las doctrinas que se autotitulan "materialistas". Debido a sucesivas "estratagemas de inmunización", las tesis fuertes e interesantes que constituían el núcleo básico de las doctrinas clásicas del materialismo se habrían difuminado en una niebla de subterfugios filosóficos. De ser así (y hay razones plausibles para suponer que a tal situación hemos llegado), esto, naturalmente, no sería un contraargumento a mi crítica del materialismo, sino un refuerzo: si por "materialismo" hoy día se entiende una docena de cosas distintas que no tienen nada que ver entre sí, entonces mejor sería usar otros rótulos menos problemáticos para cada una de ellas y enterrar para siempre ese fantasma arcaico. 


\section{Ad Quintanilla:}

Este crítico es quien más se ha concentrado en los puntos que considero fundamentales de mi discusión del materialismo, a saber, las cuestiones ontológicas y científicas, por lo que trataré todas sus objeciones con especial detalle.

Como ya he dicho más arriba, Quintanilla reconstruye adecuadamente mis dos argumentos centrales contra el materialismo: el específicamente anti-materialista y el general anti-monista. Concuerda en parte con el segundo, pero no con el primero; es más, según él, los dos argumentos son mutuamente contradictorios: si el segundo es válido, no lo puede ser el primero. En efecto, arguye, para que la premisa central del segundo argumento (la de que la realidad posee diversas propiedades fundamentales mutuamente irreducibles) sea válida, es necesario presuponer que la investigación científica puede determinar cuáles son las verdaderas propiedades de las cosas (con lo cual concuerdo); y de ahí infiere: "Si conocemos propiedades reales de las cosas reales, entonces el materialista puede decir con sentido que conocemos parcialmente la materia" ("La crítica del materialismo", p. 82). Por tanto, concluye Quintanilla, el primer argumento sobre la irremediable oscuridad del concepto de materia no es aceptable.

Me parece claro que la inferencia que he entrecomillado es un non sequitur. Admitir que conocemos "propiedades reales de las cosas reales" no implica la plausibilídad del materialismo. Una cosa no tiene que ver con la otra. Como ya he indicado antes, es inadecuado identificar "lo real" con "lo material", pues lo primero es una categoría epistemológica y lo segundo una ontológica. (Recuérdese que no hay que confundir realismo con materialismo.) El partidario de una ontología espiritualista también podría sostener que él conoce las "propiedades reales de las cosas reales" (que en ese caso serían "cosas espirituales"). Quizás el materialista quiera replicar que un espiritualista, justamente por serlo, no puede "conocer las propiedades reales de las cosas rea- 
les". Pero ésa es justamente la asunción que se está cuestionando; su validez no puede admitirse a priori; el peso de la prueba recae sobre el materialista.

En cuanto al segundo argumento que presenté, aunque Quintanilla admite su validez en principio, sostiene que no refuta el materialismo, al menos la forma de materialismo que él sostiene: su materialismo pretende ser compatible con una ontología pluralista. Para ello considera concretamente una definición de materia adecuada a este fin: "materia es todo lo que tiene cualquiera de las propiedades que la ciencia atribuye a las cosas" (op. cit., p. 83).

Este es otro caso típico de trivialización o tautologización del materialismo, como he explicado en $\oint 1$. Prescindiendo del hecho de que proponer un "materialismo pluralista" me suena análogo a tratar de dibujar un "cuadrado redondo", la definición de materia propuesta para evitar los problemas de un materialismo ontológicamente comprometido hace tanto a la una como al otro enteramente vacíos de contenido. Decir que materia es cualquier cosa que la ciencia afirma que hay no es decir gran cosa; y comprometerse con una doctrina (el "materialismo" así entendido) que lo único que sostiene es que hay las cosas que la ciencia dice que hay, no es tampoco comprometerse mucho. A lo más a lo que uno se compromete aquí es a una vaga forma de cientificismo, no al materialismo. Por añadidura, el relativismo inherente a esta noción de materia y al materialismo concomitante nos podría llevar a consecuencias desastrosas para cualquier concepción del universo que remotamente se parezca al materialismo: la ciencia de hace tres siglos, la de Kepler, Van Helmont y Newton, atribuía a las cosas propiedades (por ejemplo: relaciones místico-platónicas entre las órbitas planetarias; efluvios espirituales de las sustancias químicas; principios espirituales de atracción y repulsión originados en la

5 No estoy seguro de que Quintanilla mismo desee proponer esta definición como el núcleo del materialismo - el tono general de su artículo es más cauto. Sin embargo, por si acaso, y dado que he of́do esa definición en boca de muchos soi-disant materialistas, creo que valo la pena extenderse sobre ella. 
teleología divina, etc., etc.) que nadie, ni entonces ni hoy, consideraría compatibles con una ontología materialista. Y aunque nos forcemos a afirmar que todas las propiedades reales de las cosas admitidas por la ciencia actual son, por definición, propiedades materiales (lo cual es muy forzado), no sabemos qué ocurrirá dentro de trescientos años: ¿qué habría de decir el materialista actual que resucitara dentro de un par de siglos y se encontrara con una ciencia que admitiera la realidad irreductible de entidades astrológicas, parapsicológicas y hasta (¿qué sorpresa!) de estados mentales cotidianos como creencias e intenciones? Decir: "materia es todo lo que tiene cualquiera de las propiedades que la ciencia atribuye a las cosas" es prácticamente decir que la materia, y por tanto el materialismo, puede ser cualquier cosa y que el materialista sólo se compromete a estar con la ciencia del momento pase lo que pase: una forma de oportunismo filosófico.

Quintanilla plantea otra cuestión más técnica y de discusión más complicada, pero en cualquier caso de suma importancia para una ontología de la ciencia. Al considerar mis argumentos en contra del reduccionismo materialista, dice concordar con mi tesis anti-reduccionista general, pero no con los términos específicos con que trato de sustentarla. En mi artículo de 1977 mencioné, como cosas que forzosamente le han de producir quebraderos de cabeza a un materialista que quiera seguir de cerca la ciencia moderna, "entidades tales como ondas de probabilidad, energía interna, entropía, puntos espaciotemporales, etc." Quintanilla critica mi uso de esta terminología: los términos en cuestión no se referirían a entidades, sino a propiedades de entidades. Su malestar ante mi uso terminológico está, efectivamente, en gran parte justificado; lo menos que puede decirse de él es que es descuidado. No creo que este uso (negligente) de terminología física sea tan esencial a mi argumento como Quintanilla supone; de todos modos vale la pena aclarar este punto por su importancia intrínseca.

En primer lugar, conviene aclarar que lo que constituirá 
la ontología básica de las teorias físicas serán entidades admitidas en sus dominios de definición correspondientes, es decir, lo que se admite como argumentos (individuos) de las funciones métricas en una reconstrucción lógica adecuada de dichas teorías. (Los argumentos son las "entidades"; las funciones, sus "propiedades".) Ahora bien, no siempre está claro, en el uso negligente de los términos técnicos por parte de los físicos, si están hablando de un argumento o de una función. Esto puede ser un problema difícil de decidir, y la decisión no siempre será completamente no-arbitraria.

De las "cosas" problemáticas para el materialista que yo mencioné en mi artículo, hay algunas que son claramente funciones y no individuos del dominio básico (es decir, "propiedades" y no "entidades"). Es el caso de "energia" y "entropía". Otros casos no son tan claros: de "campo electromagnético" y "ondas de probabilidad" creo que puede decirse actualmente que dentro de ciertas teorías aparecen sin duda como funciones, pero en otras exposiciones parecen admitirse como individuos irreductibles del dominio básico. Esto es particularmente el caso para "campo". No debería asombrarnos esta situación ambigua, pues los físicos son ambiguos, las teorías que ellos producen también lo son, y su reconstrucción lógica en muchos casos todavía está en ciernes (o en el limbo). Nos enfrentamos aquí a un problema genuino de filosofía de la física con profundas consecuencias ontológicas generales, y un mérito del trabajo de Quintanilla es hacernos reflexionar sobre este punto, Ahora bien, todo lo que podemos decir de momento es que nos enfrentamos a una tarea importante a resolver por cualquier programa futuro de reconstrucción lógica de la física.

En el caso de las entidades espaciotemporales hay que admitir que existen ya reconstrucciones adecuadas de teorías fundamentales de la física donde, o bien aparecen puntos espaciales e instantes temporales, o bien puntos espaciotemporales como parte del dominio básico de definición de las funciones. Y no es válido calificarlos de puras "ficciones matemáticas", como hace Quintanilla: verdaderas ficcio- 
nes matemáticas utilizadas en física son, por ejemplo, los números imaginarios; en cambio, los elementos del espacio y tiempo, que tienen plena interpretación física, no pueden compararse a tales ficciones. Si posiciones espaciales e intervalos temporales hubieran de tomarse como meras ficciones debido a su carácter idealizado y matematizado, entonces con la misma razón deberíamos considerar ficticias partículas y campos. Por ello no puedo admitir la crítica de Quintanilla en este punto particular. Sigo creyendo que espacio y tiempo constituyen un verdadero problema para una ontología materialista.

Aparte de ello, el hecho de que algunos de los conceptos que mencioné, como "entropia", deban considerarse propiamente como refiriéndose a funciones y no a individuos, no les quita su carácter problemático para el materialismo. En efecto, el problema que yo quería hacer notar con tales conceptos es que no está claro que las teorías que los contienen sean reducibles a una teoría con ontología básica materialista (como podría ser una teoría atómica). Además, aunque se trate de funciones y no de individuos, sigue en pie la cuestión de averiguar cuál es la naturaleza del dominio de definición de tales funciones, es decir, averiguar la naturaleza de sus argumentos. Por ejemplo, ¿cuáles son los individuos básicos apropiados para una teoría que contenga la entropía? Quintanilla no nos lo dice, y por mi parte dudo de que, sea cual sea la reconstrucción propuesta, aparezcan en ésta como argumentos de la entropía entidades claramente materiales (en un sentido no ad hoc de "material").

Concuerdo plenamente con la observación final de Quin. tanilla en que la forma más fructífera de discutir problemas de ontología de la ciencia, y en particular, de una posible ontología materialista, es dentro del marco de teorías axiomatizadas. Un materialismo axiomatizado sería, al menos, un materialismo claro y controlable, y ésta es una de las

6 En mi reconstrucción de la termodinámica (en Erkenntnis, 1975) introduje estados como individuos básicos. Es dudoso que tales entes sean compatibles con una genuina ontología materialista. 
máximas (e infrecuentes) virtudes de que puede hacer gala una doctrina filosófica. Mi problema, no obstante, es que aún no conozco ningún candidato plausible a tal forma de materialismo. El candidato que propone Quintanilla es la ontología de Bunge, de aparición reciente en su Treatise on Basic Philosophy. No puedo ni quiero entrar aquí en una discusión general de la ontología bungiana; esto nos llevaría demasiado lejos. Afortunadamente para la presente discusión, el propio Quintanilla resume lo que, a su entender, son los dos principios básicos del "materialismo" de Bunge: "(i) que en el mundo hay entidades dotadas de propiedades, pero no propiedades que no lo son de nada en concreto; (ii) que nuestras teorías son representaciones de las propiedades de las cosas y que una representación de una cosa no es lo mismo que la cosa" (op. cit., p. 85).

Después de la forma en que he venido discutiendo el materialismo en mi artículo anterior y en éste, creo innecesario hacer ver al lector por qué, a mi entender, ninguno de esos dos principios tiene nada que ver con una ontología materialista. Tomados en conjunto, son simplemente una forma de realismo epistemológico anti-platónico (el segundo principio subraya el elemento realista, mientras que el primero excluye el platonismo). Es fácil ver que estos principios son compatibles con ontologías claramente no-materialistas. Podemos hacer el test con nuestra piedra de toque consuetudinaria: una ontología espiritualista proto = leibniziana que sostenga que el universo está constituido por mónadas espirituales. Tal ontología puede coherente y naturalmente incluir entre sus principios: (i) que las mónadas poseen propiedades (espirituales), pero no hay ninguna propiedad que no lo sea de alguna mónada; y (ii) que nuestras representaciones de las mónadas no son lo mismo que las mónadas. No hay ninguna dificultad en traducir los principios bungianos a una ontología espiritualista.

\footnotetext{
1 Supongo que es totalmente superfluo hacer notar en este punto que no estoy abogando ni por los principios de Bunge ni por una monadología espiritualista, ni por nada parecido. Espero que a estas alturas ya haya quedado
} 
3. Finalmente, quisiera hacer una aclaración sobre el último párrafo de mi artículo de 1977 , el cual, al parecer, ha provocado un gran malestar, cuando no el sarcasmo, en algunos de mis críticos. Terminé mi artículo anterior con lo que llamé una "confesión personal": la proclamación de mis simpatías por la actitud vital implícita o explícita en el materialismo, si bien soy incapaz de suscribirme a él como tesis ontológica. Coincido empáticamente con el materialismo en rechazar actitudes vitales de tipo romántico y místico. Algunos han sentido que este tipo de proclamaciones de sentimientos está fuera de lugar en un artículo filosófico serio. Villanueva empieza su comentario: "Moulines se confiesa no-materialista. Afortunadamente hay algo más que una confesión personal"; Rodríguez Tirado ironiza preguntándose si gozo o no leyendo a místicos y románticos como Juan de la Cruz y Shelley.

En general, concuerdo con quienes rechazan las proclamaciones de fe personal en trabajos filosóficos. Las discusiones filosóficas deberían ser lo más despersonalizadas posible, tanto en su contenido como en su forma. Este es un principio general de metodología filosófica. Sin embargo, como todo principio general, puede ser matizado o debilitado en algunos casos. Hay temas de discusión filosófica que, por las razones que sean, yan inevitablemente ligados a evaluaciones y actitudes personales. Uno de ellos es el problema del materialismo, como se echa de ver por las reacciones emocionales que subrepticia o abiertamente ha provocado la lectura del artículo en cuestión en muchas personas.

En el debate milenario en torno al materialismo, con demasiada frecuencia se ha atacado esta posición debido a motivaciones filosóficamente inadmisibles, por ejemplo, motivaciones religiosas, éticas y hasta estéticas. No creo que sea una exageración decir que, a lo largo de los dos mil años de historia del materialismo, la gran mayoría de autores que han

suficientemente claro que en todo este artículo no estoy abogando por nada en absoluto. Mi único propósito es "blanquista": hacer ver que el materialismo no funciona; lo que vaya a sustituirlo, ya se verá. 
polemizado con esta doctrina lo han hecho no tanto a consecuencia de un análisis conceptual desapasionado, sino porque sencillamente se les revolvían las tripas. Cuando redacté mi artículo quise puntualizar que mi crítica al materialismo no provenía de ese lado.

Rodríguez Tirado me conmina a argumentar por qué la actitud vital del materialista me parece más valiosa humanamente que la de su contrincante habitual. No creo que el contexto de mi artículo fuera el adecuado para tratar esta cuestión. Por eso advertí que la proclamación de mis simpatías "cordiales" por el materialismo era una "confesión personal". Una argumentación sistemática en favor del materialismo en este sentido debería ser necesariamente de carácter histórico y nos llevaría a escribir un largo tratado de historia de las ideas y de la cultura. Esto, evidentemente, trascendía en mucho mi propósito original al iniciar la dis. cusión sobre el materialismo. Tampoco ahora es éste el lugar para fundamentar una evaluación histórica del papel jugado por el materialismo en el desarrollo de la cultura occidental. Sin embargo, aunque sea sin el fundamento de una erudita exposición histórica, quisiera sentar la tesis (que, por lo demás, me parece históricamente obvia) de que, desde la antigüedad hasta las primeras décadas de este siglo, la actitud materialista jugó un papel decisivo y positivo en el proceso de liberación de temores supersticiosos, opresiones por parte de poderes eclesiásticos y políticos, hipocresías morales, inhibiciones sexuales, y tantos otros sistemas inventados por los seres humanos para hacerse sufrir a sí mismos innecesariamente. Los ejemplos históricos de los atomistas y sofistas griegos, los materialistas "encubiertos" del xvII, los enciclopedistas del xvIII, los "vulgomaterialistas" alemanes de mediados del xix, los ideólogos socialistas y anarquistas de la segunda mitad del xIx y principios del xx, algunos psicoanalistas radicales del $\mathrm{xx}$ y el "ala izquierda" del Círculo de Viena, todo ésos son ejemplos que hablan por sí mismos como representantes del papel histórico liberador que ha jugado lo que llamo "la actitud vital materialista". 
Ésa es la actitud a la que me refería al final de mi artículo anterior. Por desgracia, el siglo $\mathrm{xx}$ ha presenciado también el uso de la concepción materialista del universo para justificar sistemas ideológicos de opresión intelectual y nointelectual. El caso más notable y obvio es, por supuesto, el de la escolástica soviética. Otro caso, menos obvio y de menores consecuencias políticas, pero no menos preocupante para el crítico de la cultura actual, es el dogma materialista adoptado por muchos científicos naturales, que les lleva a asfixiar cualquier línea de investigación que no se conforme a la ortodoxia vigente. Pero esto último ya es otro tema, en el que no quiero ni puedo entrar ahora. Tan sólo quería señalar, a modo de conclusión, que, en mi opinión, hay razones objetivas de tipo histórico que le permiten a un espíritu crítico simpatizar con el materialismo a través de la historia (al menos hasta hace pocas décadas), a pesar de que se esté convencido de que esa concepción, en último término, ha fracasado en su intento más genuino de proporcionar una cosmovisión coherente y plausible.

\section{REFERENCIAS}

Bunge, M. Treatise on Basic Philosophy, t. I-Iv. Reidel. Dordrecht, 1974-78. Ferrater Mora, J. De la materia a la razón. Alianza Universidad. Madrid, 1979.

Moulines, C. U. "A Logical Reconstruction of Simple Equilibrium Thermodynamics". Erkenntnis, 9, I. Dordrecht, 1975.

Moulines, C. U. "Por qué no soy materialista". Crítica, 26. México, 1977.

Otero, M. H. "Sobre una clase de argumentos antimaterialistas". Crítica, 32. México, 1979.

Pereyra, C. "Sobre el materialismo. Réplica a Moulines". Episteme, 2. México, 1979.

Quintanilla, M. A. "La crítica del materialismo". Crítica, 32. México, 1979.

Rodriguez Tirado, A. "¿Qué es la materia?" Crítica, 30. México, 1978.

Villanueva, E. "Acerca de la creencia filosófica en el materialismo". Crítica, 28. México, 1978. 